\title{
Diagnostic Accuracy of Gray Scale Sonography for the Detection of Malignant Breast Tumour
}

\author{
Showkat Ara ${ }^{1 *}$, A. F. M. Arshedi Sattar², Syed Md. Sazzad Kamal'3 Md. Durrul Huda4, \\ Md. Abdullah Yusuf ${ }^{2}$, Md. Shahidul Islam ${ }^{5}$ \\ ${ }^{1}$ Department of Neuroradiology \& Imaging, National Institute of Neurosciences \& Hospital, Dhaka, Bangladesh \\ ${ }^{2}$ Department of Microbiology, National Institute of Neurosciences \& Hospital, Dhaka, Bangladesh \\ ${ }^{3} 250$ Bedded General Hospital, Jessor, Bangladesh \\ ${ }^{4}$ Department of Radiology \& Imaging, Institute of Health Technology, Rajshahi, Bangladesh \\ ${ }^{5}$ Department of Radiology \& Imaging, Sheikh Hasina Medical College, Tangail, Bangladesh \\ Email: *munny199@gmail.com, afmasattar@yahoo.com, skamal_bsmmu@yahoo.com,durruldr68@gmail.com, \\ ayusuf75@yahoo.com, shahid_bd123@yahoo.com
}

How to cite this paper: Ara, S., Sattar, A.F.M.A., Kamal, S.Md.S., Huda, Md.D., Yusuf, Md.A. and Islam, Md.S. (2019) Diagnostic Accuracy of Gray Scale Sonography for the Detection of Malignant Breast Tumour. Advances in Breast Cancer Research, 8, 112-118.

https://doi.org/10.4236/abcr.2019.83008

Received: April 4, 2019

Accepted: July 5, 2019

Published: July 8, 2019

Copyright $\odot 2019$ by author(s) and Scientific Research Publishing Inc. This work is licensed under the Creative Commons Attribution-NonCommercial International License (CC BY-NC 4.0).

http://creativecommons.org/licenses/by-nc/4.0/

\begin{abstract}
Background: Gray scale sonography is an important diagnostic tool for the detection of malignant breast tumour. Objective: The purpose of the present study was to find out the diagnostic validity gray scale sonography to detect malignant lesions of breast. Methodology: This cross-sectional study was carried out in the department of Radiology and Imaging, in collaboration with the department of Surgery and Pathology at Banghabandhu Sheikh Mujib Medical University (BSMMU), Dhaka, from July 2008 to June 2009 for a period of one year. Women presented with clinically suspected breast mass from outpatients' department (OPD) or inpatient department (IPD) were purposively selected and was Ultrasonographic diagnosis. 2-D Real-Time B-Mode Ultrasonographic examinations were done using high frequency (7.5 $\mathrm{MHz}$ ) linear transducer. Result: Test of validity was done for color Doppler Sonographic findings in evaluation of benign and malignant breast lesion. Out of 50 cases, 23 cases were true positive; 4 cases were false negative; 1 case was false positive; 22 cases were true negative confirmed by histopathology. Here sensitivity and specificity of Gray scale ultrasonography were $85.18 \%$ and $95.0 \%$ respectively. Here accuracy of Gray scale study was $90.0 \%$. Positive predictive value was $95.83 \%$ and negative predictive value was $84.61 \%$. Conclusion: Gray scale ultrasonography is a useful method in the differentiation between benign and malignant breast masses.
\end{abstract}

\section{Keywords}

Gray Scale Ultrasonography, Breast Tumour, Diagnostic Accuracy 


\section{Introduction}

Breast lesions particularly breast cancer causes some $20.0 \%$ of cancer death among females [1]. Breast cancer is the commonest cause of death in middle-aged women in western countries. Currently, one of every nine women in United States of America would develop breast cancer in their life time [2]. And virtually remain stable over the past thirty years, now being about 27 per one lac. In developing countries, it accounts for $1 \%$ to $3.0 \%$ of death [3]. Specifically, in Bangladesh, breast lesions particularly breast cancer is common clinical problem. In Bangladesh, remarkable increase of breast cancer has occurred in recent year. National Institute of cancer research from 1996 to 2000 showed cervical cancer ranked $1^{\text {st }}$ and breast cancer ranked $2^{\text {nd }}$ and the management of patients with carcinoma breast can be improved if a definitive diagnosis is obtained preoperatively by Radiological Examination [4].

The result of this study was to focus a new approach to reduce the frequency of unnecessary biopsies. Gray scale ultrasonography (USG) can detect breast mass very early due to visualization of marginal contour, calcification and echo-pattern of very small mass [5]. It can contribute to the survival benefit obtained by early breast cancer detection [6]. For developing country like Bangladesh Gray scale ultrasonography can be an easy, non ionizing, non invasive, time relieving, low cost diagnostic tool which can reduce unnecessary biopsies and surgical procedures and thus reducing morbidity and financial burden to the patient.

The purpose of this study was to assess the overall diagnostic accuracy of Gray scale USG to identify the malignant breast lesion.

\section{Methodology}

This study was performed in the Department of Radiology and Imaging at Banghabandhu Sheikh Mujib Medical University (BSMMU), Dhaka from July 2008 to June 2009 for a period of one (01) year. Patients presented with palpable breast lesions who were admitted in the surgery units of BSMMU and were diagnosed clinically as having solid breast lumps were selected as study population. The objective of the study was discussed in details with the patients before their decision to enroll themselves into the study. A detailed clinical history was taken from the patients about their symptoms like lump, duration of complains, pain, nipple discharge, nipple retraction etc. Relevant physical examinations were also done in all the cases. The patients were underwent Gray scale sonography by standard procedure [7]. Malignancy of breast lesions was detected pre-operatively. The findings were also interpreted first by the investigator and to eliminate bias the findings were confirmed by a radiologist of the department. Excision biopsy or mastectomy was done in all cases. Their postoperative findings were noted and were correlated with sonological findings. Tissues of surgically removed tumors were sent to the Department of Pathology. Their histopathology reports were collected and were then correlated with the gray scale so- 
nography findings. All this information was collected in a pre-designed data collection sheet. All the collected data was compiled and tabulated on master sheet. Statistical analyses were carried out by using the Statistical Package for Social Sciences version 16.0 for Windows (SPSS Inc., Chicago, Illinois, USA). A descriptive analysis was performed for all data. The quantitative observations were indicated by frequencies and percentages. Chi-square test and test of validity was done for color Doppler sonographic findings in evaluation of benign and malignant breast lesion. A p value was considered to be statistically significant if $<0.05$. The sensitivity, specificity, positive predictive value, negative predictive value and accuracy were calculated for the test by standard formula [4].

\section{Results}

Twenty three cases found truly malignant and 4 (four) cases were found benign as confirmed by histopathology; while of the 23 benign cases (USG diagnosis), 22 were found benign as detected by FNAC and 1(one) were found malignant which was confirmed by excisional biopsy. So, finally 28 cases were diagnosed malignant and 22 cases were benign. Thus, out of 50 cases 22 patients diagnosed as benign and 28 cases were diagnosed as malignant after performing excisional biopsy. In malignant and benign tumor more than $1.4 \mathrm{~cm}$ was found in 18 cases in each. Irregular margin was found more in malignant tumor than benign which was $16(80 \%)$ and $10(38.47 \%)$ cases respectively (Table 1$)$.

The patients suspected as malignant or benign lesion in breast by gray scale sonology were correlated with histopathological diagnosis. Out of the 50 cases 27 (54\%) cases were malignant and 23 (46\%) cases were benign in histopathological findings. On the other hand, 24 (48\%) cases were suspected as malignant and

Table 1. Distribution of all parameters compared to histopathological report $(n=50)$.

\begin{tabular}{|c|c|c|c|}
\hline Criteria & $\begin{array}{c}\text { Malignant } \\
\mathrm{n}(\%)\end{array}$ & $\begin{array}{c}\text { Benign } \\
\mathrm{n}(\%)\end{array}$ & P Value \\
\hline \multicolumn{4}{|c|}{ Size } \\
\hline$>1.4 \mathrm{~cm}$ & $18(75 \%)$ & $18(69.24 \%)$ & \multirow{2}{*}{0.001} \\
\hline$\leq 1.4 \mathrm{~cm}$ & $6(25 \%)$ & $8(30.76 \%)$ & \\
\hline \multicolumn{4}{|c|}{ Margin } \\
\hline Irregular & $16(80 \%)$ & $10(38.47 \%)$ & \multirow{2}{*}{0.001} \\
\hline Regular & $4(20 \%)$ & $16(61.38 \%)$ & \\
\hline \multicolumn{4}{|c|}{ Internal Echo } \\
\hline Hypoechoic & $4(16.66 \%)$ & $18(69.23 \%)$ & \multirow{3}{*}{0.001} \\
\hline Hyperechoic & $0(0 \%)$ & $5(19.23 \%)$ & \\
\hline Heterogenous & $20(83.34 \%)$ & $3(11.54 \%)$ & \\
\hline \multicolumn{4}{|c|}{ Calcification } \\
\hline Present & $18(75 \%)$ & $3(11.53 \%)$ & \multirow{2}{*}{0.001} \\
\hline Absent & $6(25 \%)$ & $23(88.47 \%)$ & \\
\hline
\end{tabular}


rests of the $26(52 \%)$ cases were suspected as benign in gray scale sonography. Among the 24 cases, which were suspected as malignant by gray scale sonology, one case was benign in histopathological examination. Four (4) cases were found malignant in histopathology among the suspected benign cases, which were diagnosed by gray scale sonography (Table 2).

Sensitivity, specificity, positive predictive value, negative predictive value and accuracy were $85.2 \%, 95.0 \%, 95.8 \%, 84.6 \%$ and $90.0 \%$ respectively (Table 3 ).

The ROC curve was calculated (Figure 1) and was found that area under the curve (AUC) was 0.096 (95\% CI 0.002 to 0.189 ) which was statistically significant $(\mathrm{p}=0.0001)($ Table 4$)$.

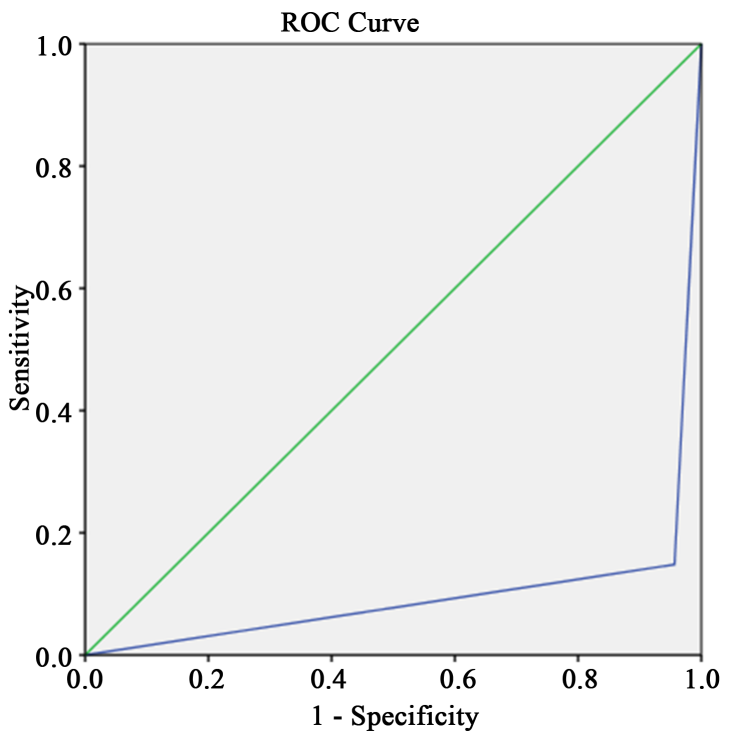

Diagonal segments are produced by ties.

Figure 1. ROC curve of the gray scale sonography.

Table 2. Association between gray scale sonography and histopathology in evaluation of malignant and benign lesion $(n=50)$.

\begin{tabular}{cccc}
\hline Gray Scale & \multicolumn{2}{c}{ Histopathological Diagnosis } & \multirow{2}{*}{ Total } \\
\cline { 2 - 3 } Sonography & Malignancy Present & Malignancy Absent & \\
\hline Malignant & 23 & 1 & 24 \\
Benign & 4 & 22 & 26 \\
Total & 27 & 23 & 50 \\
\hline
\end{tabular}

Table 3. Sensitivity, specificity, accuracy, positive and negative predictive values of the gray scale sonography in diagnosis of breast lesion.

\begin{tabular}{cc}
\hline Validity Test & Value \\
\hline Sensitivity & $85.2 \%$ \\
Specificity & $95.0 \%$ \\
Positive Predictive Value & $95.8 \%$ \\
Negative Predictive Value & $84.6 \%$ \\
Accuracy & $90.0 \%$ \\
\hline
\end{tabular}


Table 4. Area under the curve.

\begin{tabular}{cccc}
\hline \multirow{2}{*}{ Area } & \multirow{2}{*}{ P value } & \multicolumn{2}{c}{ Asymptotic 95\% Confidence Interval } \\
\cline { 3 - 4 } & & Lower Bound & Upper Bound \\
\hline 0.096 & 0.0001 & 0.002 & 0.189 \\
\hline
\end{tabular}

The test result variable(s): Gray Scale Sonography has at least one tie between the positive actual state group and the negative actual state group. Statistics may be biased. a. Under the nonparametric assumption; $b$. Null hypothesis: true area $=0.5$.

\section{Discussion}

Ultrasonography in Gray scale has been shown to be effective modality in detection breast malignancy. Gray scale evaluation has become an important investigation and is considered as most important complementary method to mammography. Thus it could be concluded that Gray scale sonography increase chance of detection of malignancy. This method prospective study was carried out in the department of Radiology and Imaging, BSMMU, hospital in collaboration with the departments of surgery and pathology department of BSMMU during the period of July 2008 to June 2009.

Gray scale Ultrasonography is very useful in the differentiation between benign and malignant breast masses [7] [8] [9] [10]. The distribution and morphology of lesions in solid breast masses seen at Gray scale ultrasound is a potentially important feature to be considered along with other sonographic criteria to predict the likelihood of malignancy [11]. Characteristic sonographic findings of benign tumors include a round or oval, slightly hypo echoic lesion with smooth borders, homogeneous internal echo, no central posterior acoustic shadowing andnormal surrounding tissue [12] [13] [14] [15] [16]. The typical features of malignancy include irregular shape, irregular margins, hypoechogenicity and central posterior acoustic shadowing.

Validity of gray scale sonography of diagnostic modality in evaluation of suspected malignant lesion has been calculated by sensitivity, specificity, positive and negative predictive values. The validity of gray scale sonography and histopathological findings were correlated by calculating sensitivity, specificity, accuracy, positive and negative predictive values by using the standard formula.

Preoperative detection of breast malignancy by Gray scale sonography and its validity by determining sensitivity, specificity, accuracy, positive predictive value and negative predictive value. The age of patients ranged from 25 to 69 years. They were divided into 5 age groups. Maximum numbers of patients with solid breast lesions were found in the 50 - 59 years age group. Among the 50 patients $46 \%$ ( 23 cases) were proved to be benign lesions and 54\% (27 cases) were diagnosed as malignant lesions. Sensitivity, specificity, accuracy, positive predictive value (PPV) and negative predictive value (NPV) were 92.59\%, 86.95\%, 90\%, $89.28 \%$ and $90.90 \%$ respectively. Similar result is reported in other studies [7] [17].

The study findings indicate that Gray scale sonographyis sensitive, specific and accurate diagnostic tool then they used as a single modality in detection of 
malignant breast lesions. Limitations of the study were short period, small sample size, inflammatory lesions in breast that give increase RI index. Gray scale sonography were performed by a single radiologist of the department, so there was chance of bias. There are some limitation of this study. This is a single centred study. Furthermore sample size is small. Updated and technologically advanced USG is not used.

\section{Conclusion}

Gray scale sonography of solid breast lesions is a sensitive, specific and accurate modality in detecting malignant solid breast lesions. In the present study, it is observed that Gray scale evaluation has a high sensitivity and accuracy. So, it can be concluded that gray scale sonography can be used as a sensitive diagnostic tool in the detection of malignant solid breast lesions. However, further research on this subject may be encouraged on large number of patients in multiple tertiary levels.

\section{Conflicts of Interest}

There is no conflict of interest to any of the authors of this article.

\section{References}

[1] Dellaportas, D., Koureas, A., Contis, J., Lykoudis, P.M., Vraka, I., Psychogios, D., Kondi-Pafiti, A. and Voros, D.K. (2015) Contrast-Enhanced Color Doppler Ultrasonography for Preoperative Evaluation of Sentinel Lymph Node in Breast Cancer Patients. Breast Care, 10, 331-335. https://doi.org/10.1159/000436958

[2] Hu, Q., Wang, X.Y., Zhu, S.Y., Kang, L.K., Xiao, Y.J. and Zheng, H.Y. (2015) Meta-Analysis of Contrast-Enhanced Ultrasound for the Differentiation of Benign and Malignant Breast Lesions. Acta Radiologica, 56, 25-33.

https://doi.org/10.1177/0284185113517115

[3] Choi, H.Y., Kirn, H.Y., Baek, S.Y., Kang, B.C. and Lee, S.W. (2000) Significance of Resistive Index in Color Doppler Ultra sonogram: Differentiation between Benign and Malignant Breast Masses. Clinical Imaging, 23, 284-288.

https://doi.org/10.1016/S0899-7071(99)00152-7

[4] Elkharbotly, A. and Farouk, H.M. (2015) Ultrasound Elastography Improves Differentiation between Benign and Malignant Breast Lumps Using B-Mode Ultrasound and Color Doppler. The Egyptian Journal of Radiology and Nuclear Medicine, 46, 1231-1239. https://doi.org/10.1016/j.ejrnm.2015.06.005

[5] Cotran, R.S., Kumar, V. and Collins, T. (2000) Robbins Basis of Disease. 6th Edition, WB Saunders, Philadelphia, 1119-1152.

[6] Mattoon, J.S. and Nyland, T.G. (2015) Fundamentals of Diagnostic Ultrasound. In: Small Diagnostic Ultrasound, WB Saunders, Philadelphia, 1-49.

https://doi.org/10.1016/B978-1-4160-4867-1.00001-5

[7] Kovatcheva, R., Guglielmina, J.N., Abehsera, M., Boulanger, L., Laurent, N. and Poncelet, E. (2015) Ultrasound-Guided High-Intensity Focused Ultrasound Treatment of Breast Fibroadenoma-A Multicenter Experience. Journal of Therapeutic Ultrasound, 3, 1. https://doi.org/10.1186/s40349-014-0022-3

[8] Folkman, J. (1995) Clinical Applications of Research on Angiogenesis. The New 
England Journal of Medicine, 333, 1757-1763.

https://doi.org/10.1056/NEJM199512283332608

[9] Godavarty, A., Rodriguez, S., Jung, Y.J. and Gonzalez, S. (2015) Optical Imaging for Breast Cancer Prescreening. Breast Cancer. Targets and Therapy, 7, 193. https://doi.org/10.2147/BCTT.S51702

[10] Zhang, L., Li, J., Xiao, Y., Cui, H., Du, G., Wang, Y., Li, Z., Wu, T., Li, X. and Tian, J. (2015) Identifying Ultrasound and Clinical Features of Breast Cancer Molecular Subtypes by Ensemble Decision. Scientific Reports, 5, Article No. 11085. https://doi.org/10.1038/srep11085

[11] Fornage, B.D., Sneige, N., Faroux, M.J. and Andry, E. (2004) Sonographic Appearance and Ultrasound Guided Fine-Needle Aspiration Biopsy of Breast Carcinomas Smaller than $\mathrm{I} \mathrm{cm}^{3}$. Journal of Ultrasound in Medicine, 23, 887-894.

[12] Ibrahim, R., Rahmat, K., Fadzli, F., Rozalli, F.I., Westerhout, C.J., Alli, K., Vijayananthan, A. and Moosa, F. (2016) Evaluation of Solid Breast Lesions with Power Doppler: Value of Penetrating Vessels as a Predictor of Malignancy. Singapore Medical Journal, 57, 634. https://doi.org/10.11622/smedj.2016001

[13] Park, A.Y., Seo, B.K., Woo, O.H., Jung, K.S., Cho, K.R., Park, E.K., Cha, S.H. and Cha, J. (2018) The Utility of Ultrasound Superb Microvascular Imaging for Evaluation of Breast Tumour Vascularity: Comparison with Colour and Power Doppler Imaging Regarding Diagnostic Performance. Clinical Radiology, 73, 304-311. https://doi.org/10.1016/j.crad.2017.10.006

[14] Shin, H.J., Kim, H.H. and Cha, J.H. (2015) Current Status of Automated Breast U1trasonography. Ultrasonography, 34, 165-172. https://doi.org/10.14366/usg.15002

[15] Chan, C.H., Coopey, S.B., Freer, P.E. and Hughes, K.S. (2015) False-Negative Rate of Combined Mammography and Ultrasound for Women with Palpable Breast Masses. Breast Cancer Research and Treatment, 153, 699-702. https://doi.org/10.1007/s10549-015-3557-2

[16] Skerl, K., Vinnicombe, S., Giannotti, E., Thomson, K. and Evans, A. (2015) Influence of Region of Interest Size and Ultrasound Lesion Size on the Performance of 2D Shear Wave Elastography (SWE) in Solid Breast Masses. Clinical Radiology, 70, 1421-1427. https://doi.org/10.1016/j.crad.2015.08.010

[17] Williams, N., O’Connell, P.R. and McCaskie, A. (2018) Bailey \& Love's Short Practice of Surgery. The Collector's Edition, CRC Press, Boca Raton. 